\title{
Evaluation of oxidative stress in pregnants with chronic hepatitis $B$ and $C$
}

\author{
๑Mustafa Akar ${ }^{1}$, $\odot$ Gülden Başkol ${ }^{2}$, $₫$ Mehmet Yücesoy $^{3}$ \\ ${ }^{1}$ University of Health Sciences, Bursa Yüksek İhtisas Training and Research Hospital, Department of Gastroenterology, Bursa, Turkey \\ ${ }^{2}$ Erciyes University, Faculty of Medicine, Department of Biochemistry, Kayseri, Turkey \\ ${ }^{3}$ Erciyes University, Faculty of Medicine, Department of Gastroenterology, Kayseri, Turkey
}

Cite this article as: Akar M, Başkol G, Yücesoy M. Evaluation of oxidative stress in pregnants with chronic hepatitis B and C. Anatolian Curr Med J 2021; 3(1); 20-25.

\begin{abstract}
Aim: This study was aimed to investigate the levels of antioxidant markers (paraoxonase, superoxide dismutase, glutathione peroxidase, and thiol) and oxidative stress markers (advanced oxidation protein products, xanthin oxidase, nitric oxide, malondialdehyde, and 8-hydroxydeoxyguanosine) in pregnant women with chronic hepatitis B and C.

Material and Method: Sixty pregnant women in the last trimester, 20 of whom had chronic hepatitis B, another 20 of whom had chronic hepatitis $\mathrm{C}$, and the remaining 20 of whom were healthy controls, were enrolled in this study. Demographic, clinical and laboratory data were recorded for all patients.

Results: When compared to the healthy controls, the pregnant women with chronic hepatitis B and C displayed significantly lower levels of paraoxonase, glutathione peroxidase, and thiol $(\mathrm{p}<0.001)$. Superoxide dismutase levels were also lower in the chronic hepatitis $\mathrm{B}$ and $\mathrm{C}$ patients, in comparison to the healthy controls, yet this difference was statistically insignificant $(\mathrm{p}=0.76)$. Compared to the healthy controls, the chronic hepatitis B and C patients had significantly higher levels of advanced oxidation protein and xanthine oxidase $(\mathrm{p}<0.001)$. The nitric oxide levels of the chronic hepatitis $\mathrm{B}$ and $\mathrm{C}$ patients were significantly lower than those of the control group $(\mathrm{p}<0.05)$. No statistically significant difference was observed between the chronic hepatitis B and C patients and the controls for malondialdehyde and 8-hydroxydeoxyguanosine levels ( $\mathrm{p}>0.05)$.

Conclusion: Oxidative stress had significantly increased in pregnant women chronically infected with the hepatitis B and C viruses, when compared to healthy pregnant women. Thus, we suggest that pregnant women chronically infected with the hepatitis $\mathrm{B}$ and $\mathrm{C}$ viruses should be closely monitored throughout pregnancy for diseases induced by oxidant-antioxidant imbalance, such as preeclampsia, gestational diabetes and gestational hypertension..
\end{abstract}

Keywords: Antioxidant activity, chronic hepatitis B, chronic hepatitis C, oxidative stress, pregnancy

\section{INTRODUCTION}

Hepatitis B and C infections are a major health concern across the globe, and are described as the two primary causes of chronic hepatitis, hepatic cirrhosis and hepatocellular carcinoma $(1,2)$. According to data published by the World Health Organisation (WHO), it is estimated that, worldwide, 257 million people are chronically infected with hepatitis $B$ virus and 71 million people are chronically infected with hepatitis $C$ virus (3).

Reactive oxygen species (ROS) have an important role in the occurrence of cell and tissue damage (4). ROS can be generated under normal physiological conditions in organs with high metabolic activity. However, when ROS -due to various reasons- are generated at a level that exceeds the capacity of the antioxidant defence system, then the organism is exposed to oxidative stress (5). Superoxide $\left(\mathrm{O}_{2}{ }^{-}\right)$radicals react with hydrogen ions on the cell surface, and form the perhydroxyl radical $\left(\mathrm{HO}_{2}{ }^{\circ}\right)$. The $\mathrm{HO}_{2}{ }^{-}$radical is a stronger oxidant than the $\mathrm{O}_{2}{ }^{-\prime}$ radical. It induces toxicity by binding to the hydrophobic terminal of lipids and proteins. This mechanism is referred to as peroxidation (6).

In the bloodstream, high-density lipoprotein serves as the carrier of paraoxonase (PON). PON has an antioxidant potential and may provide protection against both macrovascular and microvascular diseases (7). By means of the dismutase reaction, the enzyme superoxide dismutase (SOD) converts $\mathrm{O}_{2}-{ }^{-}$into hydrogen peroxide $\left(\mathrm{H}_{2} \mathrm{O}_{2}\right)$, and thereby, protects cells from the toxic effects of 
$\mathrm{O}_{2}{ }^{--}$(8). SOD plays an important role in the intracellular defence mechanism of aerobic cells against the ROS (9). The liver contains high levels of catalase and glutathione peroxidase (GSH-Px), both of which are enzymes that break down peroxides in the presence of glutathione (GSH). Lipid hydroperoxides are broken down by GSHPx (10). When found at low levels, $\mathrm{H}_{2} \mathrm{O}_{2}$ breakdown occurs via GSH-Px activity, whilst when present at high levels, $\mathrm{H}_{2} \mathrm{O}_{2}$ is metabolised via catalase activity (11). It is well known that the thiol groups of albumins not only constitute the bulk of the antioxidant capacity of the human plasma, but also show effect on oxidative stress (12).

The plasma levels of advanced oxidation protein products (AOPP), which are described as protein loxidation products, are considered to be reliable markers of oxidative damage to oxidised proteins, in particular albumin (13). The generation of the $\mathrm{O}_{2}{ }^{--}$radical during the oxidation of xanthine by xanthine oxidase (XO) brings about a mechanism that produces oxidative stress $(14,15)$. The functions of nitric oxide (NO) include vasodilatation, thrombocyte aggregation, and the inhibition of the proliferation of vascular smooth muscle cells. On the other hand, due to the unpaired electron in its outer orbit, NO also acts a free radical. Therefore, pathological conditions result from both decreased and increased levels of NO. Furthermore, physiological NO levels are required for normal endothelial function $(16,17)$. Malondialdehyde (MDA) is known to lead to the polymerisation and cross bonding of membrane components. Thus, as one of the end-products of lipid peroxidation, MDA is considered to be a reliable indicator of cell damage (18). 8-hydroxydeoxyguanosine (8-OHdG), generated by the hydroxyl radical $(\mathrm{OH})$, has premutagenic effect and causes damage to the DNA. Therefore, it is considered to be a reliable marker of oxidative stress-induced DNA damage $(19,20)$.

To date, the exact underlying mechanism of hepatocyte damage associated with hepatitis B and $\mathrm{C}$ infections has not been elucidated. However, it is known that increased peroxidation and decreased antioxidant activity in chronically infected cells both contribute to the damage (9). Previous studies not only suggest that ROS and lipid peroxides contribute to the onset and advance of hepatic fibrosis, but also describe oxidative damage as a component of fibrogenesis $(18,21)$.

Blood lipid peroxide levels are generally higher in pregnant women, than in nonpregnant women. The placenta has been identified as the main source of increased levels of lipid peroxidation products. $(22,23)$. Placental oxidant-antioxidant imbalance, apart from endothelial cell damage, may also cause the passage of lipid peroxidation products into the bloodstream. This is reported to may be involved in the pathogenesis of preeclampsia, gestational diabetes (GD), and gestational hypertension (GH) $(24,25)$.

This study was aimed to investigate the levels of antioxidant markers (PON, SOD, GSH-Px, and thiol) and oxidative stress markers (AOPP, XO, NO, MDA, and $8-\mathrm{OHdG}$ ) in pregnant women with chronic hepatitis $\mathrm{B}$ and $\mathrm{C}$.

\section{MATERIAL AND METHOD}

This study was performed pursuant to the approval of the Ethics Board of Erciyes University, Faculty of Medicine (Decision Number 09/56 of the Ethics Board). All procedures were performed adhered to the ethical rules and the Helsinki Declaration of Principles.

In total, 60 women in the third trimester of pregnancy, who were admitted to the Gevher Nesibe Hospital of Erciyes University, Faculty of Medicine and the Kayseri Maternity Hospital between November 2008-November 2009, 20 of whom had chronic hepatitis B (CHB), another 20 of whom had chronic hepatitis $\mathrm{C}(\mathrm{CHC})$, and the remaining 20 of whom were healthy, were assigned to 3 study groups. Patients were enrolled in the study based on the following inclusion criteria: being in the last trimester of pregnancy with confirmed hepatitis B infection ongoing for more than 6 months (Group $\mathrm{CHB}$ ), being in the last trimester of pregnancy with confirmed hepatitis $\mathrm{C}$ infection ongoing for more than 6 months (Group CHC), and being in the last trimester of pregnancy with no associating health problem (Healthy Control Group). The following criteria were applied for exclusion from the study: having diabetes mellitus, hypertension, cardiac failure, chronic respiratory failure, acute/chronic renal failure, acute infection, fever, malignant tumour, coronary artery disease, toxaemia of pregnancy, diseases other than HBV and HCV infection that cause chronic hepatitis, toxaemic or ischaemic hepatitis, collagen tissue disease or any systemic disease, as well as smoking, and drinking alcohol. The patients enrolled in the study were informed about the trial and their formal written consent was received for participation in the study. Demographic, clinical and laboratory data were recorded for each patient. Venous blood samples were taken from each patient for the measurement of oxidative stress and antioxidant markers. The blood samples were centrifuged for the extraction of serum and plasma, which were stored under appropriate conditions until being tested. XO, GSH-Px and PON activities and thiol, MDA and AOPP levels were measured spectrophotometrically, whilst SOD activity and 8-OHdG and NO levels were measured with ELISA. 


\section{Statistical Analysis}

Study data was statistically analysed using the SPSS 15.0 software (Statistical Packages for Social Sciences; SPSS Inc., Chicago, Illinois, USA). While measurable parametric data were presented as arithmetic means \pm standard deviation $(\mathrm{x} \pm \mathrm{ss})$, measurable nonparametric data were presented as mean values (25$75 \%)$. The normality of data distribution was assessed with the Kolmogorov-Smirnov test. Differences between the study groups were assessed using oneway analysis of variance (ANOVA) (Tukey's test). Nonparametric data were analysed with the KruskalWallis test. Correlations were established with Pearson's correlation analysis. Statistical significance was set at a level of $\mathrm{p}<0.05$.

\section{RESULTS}

The demographic, clinical and laboratory data of the infected patients and healthy controls are presented in Table 1. The groups did not show any difference for age, week of pregnancy and aspartate aminotransferase, alanine aminotransferase, and gamma glutamyl transferase. Of the antioxidant markers investigated in the present study, PON, GSH-Px, and thiol levels were significantly lower in the pregnant women with $\mathrm{CHB}$ and $\mathrm{CHC}$, compared to the healthy controls $(p<0.001)$. SOD activity was also lower in the CHB and
CHC patients, in comparison to the controls, yet this difference was statistically insignificant $(\mathrm{p}=0.76)$. When compared to the controls, in the $\mathrm{CHB}$ and $\mathrm{CHC}$ patients, the oxidative stress markers AOPP and XO were found at significantly higher levels $(\mathrm{p}<0.001)$, and $\mathrm{NO}$ was determined at significantly lower levels $(\mathrm{p}<0.05)$. No significant difference was determined between the $\mathrm{CHB}$ and $\mathrm{CHC}$ patients and the healthy controls for MDA and 8 -OHdG levels $(\mathrm{p}>0.05)$. Of the oxidative stress markers investigated, $\mathrm{XO}, \mathrm{MDA}, 8-\mathrm{OHdG}$, and $\mathrm{NO}$ were higher and AOPP levels were lower in Group CHB, compared to Group $\mathrm{CHC}$, but these differences were statistically insignificant $(p>0.05)$. Of the antioxidant markers investigated, thiol was determined at significantly lower levels $(\mathrm{p}<0.001)$, and PON and GSH-Px activities were ascertained at insignificantly lower levels $(p>0.05)$ in the $\mathrm{CHB}$ patients, compared to the $\mathrm{CHC}$ patients. Another antioxidant marker, SOD activity was slightly higher in Group CHB compared to Group CHC, yet this difference was of no statistical significance $(p=0.73)$ (Table 2).

Furthermore, MDA and GSH-Px were found to be negatively correlated with each other at a moderate level (r: -0.314). While a strong negative correlation was detected between XO activity and thiol levels ( $\mathrm{r}$ : -0.626), a moderate negative correlation was found to exist between AOPP and NO levels (r: -0.314).

\begin{tabular}{|c|c|c|c|c|}
\hline Variables & Chronic hepatitis B, n: 20 & Chronic hepatitis C, n: 20 & Control, n: 20 & $\mathbf{p}$ \\
\hline Age (year) $(\mathrm{x} \pm \mathrm{ss})$ & $25.6 \pm 5.7$ & $27.5 \pm 6.1$ & $28.1 \pm 4.8$ & 0.33 \\
\hline Pregnancy week $(25-75 \%)$ & $28.5(26.5-31.5)$ & $30.5(28.0-33.5)$ & $27(26-31)$ & 0.10 \\
\hline $\operatorname{AST}^{*}(25-75 \%)(\mathrm{U} / \mathrm{L})$ & $18(16.0-22.5)$ & $15.5(13.5-19.0)$ & $16.5(15.0-19.5)$ & 0.23 \\
\hline $\operatorname{ALT}^{*}(25-75 \%)(\mathrm{U} / \mathrm{L})$ & $14.5(11-19)$ & $13(11-16)$ & $12.5(10.0-18.5)$ & 0.59 \\
\hline $\mathrm{GGT}^{*}(25-75 \%)(\mathrm{U} / \mathrm{L})$ & $10(9-14)$ & $11.5(8.5-14.0)$ & $13(10.5-15.0)$ & 0.22 \\
\hline
\end{tabular}

\section{Table 2. Comparison of antioxidant-oxidant markers between the groups}

\begin{tabular}{|c|c|c|c|c|}
\hline Antioxidant-oxidant markers & Chronic hepatitis $B^{a}, n: 20$ & Chronic hepatitis $C^{b}, n: 20$ & Control $^{\mathrm{c}}, \mathrm{n}: 20$ & $\mathbf{p}$ \\
\hline $\mathrm{PON}(\mathrm{U} / \mathrm{L})(\mathrm{x} \pm \mathrm{ss})$ & $66.8 \pm 41.3$ & $90.1 \pm 34.3$ & $138.4 \pm 44.0$ & a-c: $<0.001$ b-c: $<0.001$ \\
\hline $\mathrm{SOD}(\mathrm{U} / \mathrm{mL})(\mathrm{x} \pm \mathrm{ss})$ & $0.91 \pm 0.4$ & $0.86 \pm 0.38$ & $0.95 \pm 0.4$ & a-c: 0.76 b-c: 0.76 \\
\hline GSH-Px (U/mL) (x+ss) & $175.3 \pm 26.0$ & $189.2 \pm 25.0$ & $223.9 \pm 29.6$ & a-c: $<0.001$ b-c: $<0.001$ \\
\hline Thiol $(\mu \mathrm{mol} / \mathrm{L})(\mathrm{x} \pm \mathrm{ss})$ & $198.2 \pm 98.6$ & $336.3 \pm 116.2$ & $556.4 \pm 258.5$ & a-c: $<0.001$ b-c: $<0.001$ \\
\hline $\mathrm{AOPP}(\mu \mathrm{mol} / \mathrm{L})(\mathrm{x} \pm \mathrm{ss})$ & $211.6 \pm 31$ & $249.6 \pm 50.7$ & $122.7 \pm 30$ & a-c: $<0.001$ b-c: $<0.001$ \\
\hline $\mathrm{XO}^{*}(\% 25-75)(\mathrm{U} / \mathrm{mL})$ & $5.4(3.9-7.7)$ & $4.0(3.7-4.5)$ & $3.2(3.0-3.5)$ & a-c: $<0.001$ b-c: $<0.001$ \\
\hline $\mathrm{NO}(\mu \mathrm{mol} / \mathrm{L})(\mathrm{x} \pm \mathrm{ss})$ & $4.7 \pm 2.5$ & $3.9 \pm 2.2$ & $6.4 \pm 2.0$ & a-c: 0.02 b-c: 0.01 \\
\hline $\operatorname{MDA}(\mu \mathrm{mol} / \mathrm{L})(\mathrm{x} \pm \mathrm{ss})$ & $0.80 \pm 0.04$ & $0.78 \pm 0.09$ & $0.80 \pm 0.07$ & a-c: 0.42 b-c: 0.42 \\
\hline 8-OHdG (ng/mL) (x $\pm s s)$ & $0.88 \pm 0.09$ & $0.88 \pm 0.08$ & $0.90 \pm 0.04$ & a-c: 0.81 b-c: 0.81 \\
\hline
\end{tabular}

*: The median value was given because the distribution was nonparametric, PON: paraoxanase, SOD: superoxide dismutase, GSH-Px: glutathione peroxidase, AOPP: advanced oxidation protein products, XO: xanthine oxidase, NO: nitric oxide, MDA: malondialdehyde, 8-OHdG: 8-Hydroxideoxyguanosine. 


\section{DISCUSSION}

Multiple studies have shown decreased serum paraoxonase and arylesterase activity in patients with chronic hepatitis (26-29). Furthermore, cases of pregnancy toxaemia have been associated with decreased serum PON and arylesterase activities (30). The results we detected for the PON levels are in agreement with the results of the majority of available literature reports.

Studies are available, which indicate that, when compared to healthy controls, SOD activity is weaker in patients with chronic hepatitis (31-36). On the other hand, another report indicates that the SOD activity of untreated $\mathrm{CHC}$ patients (n:20) was higher than that of the control subjects $(\mathrm{p}<0.05)(37)$. In the present study, SOD activity was higher in the control group, compared to the chronic hepatitis groups, but this difference was statistically insignificant (p: 0.76). The difference observed between the infected groups and the healthy control group for $\mathrm{SOD}$ activity being statistically insignificant was attributed to the groups being comprised of small numbers of patients.

While the majority of previous research have demonstrated significantly lower GSH-Px activity in patients with chronic hepatitis, compared to healthy controls $(31,32,36,38,39)$, one study has pointed out to no difference in the activity of this enzyme between infected and healthy individuals (37), and yet another study has reported a higher activity of this enzyme in hepatitis patients (34). In the current study, while the chronic hepatitis groups had GSH-Px activities lower than that of the controls $(p<0.001)$. These results are in agreement with several literature reports. In a study conducted by Romero et al. (40), it was determined that high levels of MDA, an end product of LP, inhibited GSH-Px activity in patients infected with HCV. In agreement with this particular report, we demonstrated a negative correlation between GSH-Px activity and MDA levels (r: -0.314).

This study revealed that, thiol levels of the chronic hepatitis groups were found to be significantly lower than those of the control group ( $<<0.001)$. Furthermore, the thiol levels of the CHB group were significantly lower than those measured in the CHC group $(\mathrm{p}<0.001)$. The thiol levels measured in the diseased groups being lower than those measured in the control group was attributed to the failure of the antioxidant mechanism of proteins, which would eventually result in the oxidation of human serum albumins, in association with increased AOPP levels. Low thiol levels could also be related to the negative correlation determined between $\mathrm{XO}$ activity and thiol levels ( $\mathrm{r}$ : -0.626), and/or the associating antioxidant property of thiol.

Zuwala-Jagiello et al. (41) determined that, among a total of 34 patients with Child-Pugh stage A compensated hepatic cirrhosis (n:18) and Child-Pugh stage B and C decompensated hepatic cirrhosis (n:16), serum AOPP levels were significantly lower in the group of patients with compensated cirrhosis, compared to the group of patients with decompensated cirrhosis $(\mathrm{p}<0.05)$. Llurba et al. (42) reported that AOPP levels did not differ between preeclampsia patients and healthy controls. In the present study, the AOPP levels of the chronic hepatitis groups were significantly higher than those of the controls $(p<0.001)$. Furthermore, a moderate negative correlation was determined to exist between AOPP and NO levels in this study (r: -0.314). This correlation was attributed to the negative impact induced by oxidative stress on $\mathrm{NO}$ synthesis, and the increase in AOPP levels, which is a marker of oxidative stress.

It has been reported that many diseases are associated with increased XO activity linked to increased oxidative stress (43-45). Battelli et al. (46) measured significantly higher XO activity in the group with chronic hepatic disease, when compared to the healthy control group $(p<0.05)$. Similarly, when compared to the controls, the chronic hepatitis groups displayed significantly higher $\mathrm{XO}$ activities in this study $(\mathrm{p}<0.001)$.

Assem et al. (47) detected no increase in levels of nitrate, a metabolite of NO, in patients with chronic active hepatitis and Child-Pugh stage A hepatic cirrhosis, compared to the control group. However, they determined nitrate levels to have significantly increased Child-Pugh stage B and $C$ hepatic cirrhosis groups, when compared to the control group $(p=0.01)$. In the current study, the NO levels of the chronic hepatitis groups were significantly lower than those of the control group $(\mathrm{p}<0.05)$. The NO levels of the groups with chronic hepatitis having been determined to be lower than those of the control group was attributed to the presence of oxidative stress-induced endothelial damage and the resulting negative impact on NO synthesis.

While some literature reports have indicated higher MDA levels in patients with viral hepatitis, compared to controls $(31,32,37,48)$, one report has indicated no difference between chronic hepatitis groups and healthy controls for this parameter (33). This study showed that, no statistically significant difference was observed between the control group and the chronic hepatitis groups for MDA levels ( $\mathrm{p}=0.42$ ).

In a study, positive immunohistochemical staining for 8-OHdG was investigated in hepatocytes from liver biopsy specimens. The researchers ascertained that positive $8-\mathrm{OHdG}$ staining of the hepatocytes was stronger in $\mathrm{CHC}$ group, compared to $\mathrm{CHB}$ group $(p<0.001)(49)$. In another study by Kitada et al. (50), both histological activity index (HAI) and positive 
immunohistochemical staining for 8-OHdG were investigated in 12 patients with chronic hepatitis of different etiology. These researchers determined that the HAI and positive 8-OHdG immunohistochemical staining were positively correlated with each other ( $\mathrm{r}: 0.68, \mathrm{p}<0.05)$. In the present study, no significant difference was determined between any of the groups for $8-O H d G$ levels $(p>0.05)$. The results of the present study being in disagreement with the results previously reported could be attributed to method differences between the studies.

\section{Limitations of the Study}

- i-) Since the patients with chronic hepatitis B or C infection were pregnant, liver biopsy could not be performed. Therefore, the degree of liver disease in these patients was not known exactly.

- ii-) In the current study, the number of patients in the groups can be considered insufficient for statistical evaluations.

\section{CONCLUSION}

It was determined that, compared to the healthy controls, oxidative stress had significantly increased in pregnant women chronically infected with the hepatitis B and C viruses. Therefore, it is suggested that pregnant women with the hepatitis $B$ and $C$ viruses should be closely monitored throughout pregnancy for diseases such as preeclampsia, gestational diabetes and gestational hypertension, the pathogenesis of which involve oxidantantioxidant imbalance.

\section{ETHICAL DECLARATIONS}

Ethics Committee Approval: The study was carried out with the permission of Ethics Board of Erciyes University, Faculty of Medicine (Decision Number 09/56 of the Ethics Board).

Informed Consent: Written informed consent was obtained from all participants who participated in this study.

Referee Evaluation Process: Externally peer-reviewed. Conflict of Interest Statement: The authors have no conflicts of interest to declare.

Financial Disclosure: Scientific Research Project support was received from Erciyes University Research Fund.

Author Contributions: All of the authors declare that they have all participated in the design, execution, and analysis of the paper, and that they have approved the final version.

\section{REFERENCES}

1. Pardee M. Diagnosis and management of Hepatitis B and C. Nurs Clin North Am 2019; 54: 277-84.

2. Hyun Kim B, Ray Kim W. Epidemiology of Hepatitis B Virus Infection in the United States. Clin Liver Dis (Hoboken) 2018; 12: $1-4$

3. Global Hepatitis Report 2017. Geneva: World Health Organization; 2017. Available at: http: //apps.who.int/iris / handle/10665/255016. Accessed October 01, 2020.

4. Sinclair AJ, Barnett AH, Lunec J. Free radicals and antioxidant systems in health and disease. Br J Hosp Med. 1990; 43: 334-44.

5. Şentürk H. Serbest radikal hasarının hepato-biliyer sistem hastalıklarındaki rolü. Kocatepe Tip Derg 2004; 5: 1-8.

6. Bingöl S, Aydın S, Açıkgöz Ş. Free radicals. Medical Journal of Ankara Hospital. 1993; 28: 2, Supp.1.

7. Mackness MI, Durrington PN, Ayub A, Mackness B. Low serum paraoxonase: a risk factor for atherosclerotic disease? Chem Biol Interact. 1999; 119-120: 389-97.

8. Valko M, Rhodes CJ, Moncol J, Izakovic M, Mazur M. Free radicals, metals and antioxidants in oxidative stress-induced cancer. Chem Biol Interact 2006; 160: 1-40.

9. Stehbens WE. Oxidative stress in viral hepatitis and AIDS. Experimental and Molecular Pathology, 2004; 77: 121-32.

10. Ames BN, Shigenaga MK, Hagen TM. Oxidants, antioxidants, and the degenerative diseases of aging. Proc Natl Acad Sci U S A. 1993; 90: 7915-22.

11. Memişoğulları R. Diyabettte serbest radikallerin rolü ve antioksidanların etkisi. Düzce Tip Fakültesi Derg 2005; 3: 30-39.

12. Himmelfarb J, McMenamin E, McMonagle E. Plasma aminothiol oxidation in chronic hemodialysis patients. Kidney Int 2002; 61: 705-16.

13. Witko-Sarsat V, Gausson V, Nguyen AT, et al. AOPP-induced activation of human neutrophil and monocyte oxidative metabolism: a potential target for $\mathrm{N}$-acetylcysteine treatment in dialysis patients. Kidney Int 2003; 64: 82-91.

14. Akyol O, Gökbulut I, Köksal N, Akin H, Ozyurt H, Yildirim Z. The activities of purine catabolizing enzymes in plasma and bronchial washing fluid in patients with lung cancer and pneumonia. Clin Biochem 2001; 34: 251-54.

15. Irmak MK, Koltuksuz U, Kutlu NO, et al. The effect of caffeic acid phenethyl ester on ischemia-reperfusion injury in comparison with alpha-tocopherol in rat kidneys. Urol Res 2001; 29: 190-93.

16. Cuzzocrea S, Riley DP, Caputi AP, Salvemini D. Antioxidant therapy: a new pharmacological approach in shock, inflammation, and ischemia/reperfusion injury. Pharmacol Rev 2001; 53: 13559.

17. Moro MA, Russel RJ, Cellek S, et al. cGMP mediates the vascular and platelet actions of nitric oxide: confirmation using an inhibitor of the soluble guanylyl cyclase. Proc Natl Acad Sci U S A. 1996; 93: 1480-85.

18. Kaçmaz B, Öğüs $\mathrm{E}$, Paşaoğlu $\mathrm{H}$, et al. Akut ve kronik viral hepatitli hastalarda lipid peroksidasyonu ve oksidasyona direncin incelenmesi. Viral Hepatit Dergisi 2001; 7: 374-78.

19. Shigenaga MK, Gimeno CJ, Ames BN. Urinary 8-hydroxy-2'deoxyguanosine as a biological marker of in vivo oxidative DNA damage. Proc Natl Acad Sci U S A. 1989; 86: 9697-701.

20. Kasai H. Analysis of a form of oxidative DNA damage, 8-hydroxy2'-deoxyguanosine, as a marker of cellular oxidative stress during carcinogenesis. Mutat Res. 1997; 387: 147-63.

21. Loguercio C, Federico A. Oxidative stress in viral and alcoholic hepatitis. Free Radic Biol Med 2003; 34: 1-10.

22. Little RE, Gladen BC. Levels of lipid peroxides in uncomplicated pregnancy: a review of the literature. Reprod Toxicol. 1999; 13: 347-52. 
23. Hubel CA, Roberts JM, Taylor RN, Musci TJ, Rogers GM, McLaughlin MK. Lipid peroxidation in pregnancy: new perspectives on preeclampsia. Am J Obstet Gynecol. 1989; 161: 1025-34.

24. Poranen AK, Ekblad U, Uotila P, Ahotupa M. Lipid peroxidation and antioxidants in normal and pre-eclamptic pregnancies. Placenta. 1996; 17: 401-05.

25. Cester N, Staffolani R, Rabini RA, et al. Pregnancy-induced hypertension: a role for peroxidation in microvillus plasma membranes. Mol Cell Biochem 1994; 131: 151-5.

26. Aslan M, Horoz M, Nazligul Y, et al. Serum paraoxonase and arylesterase activities for the evaluation of patients with chronic hepatitis. Int J Clin Pract 2008; 62: 1050-5.

27. Ferré N, Camps J, Prats E, et al. Serum paraoxonase activity: a new additional test for the improved evaluation of chronic liver damage. Clin Chem 2002; 48: 261-8.

28. Kilic SS, Aydin S, Kilic N, Erman F, Aydin S, Celik I. Serum arylesterase and paraoxonase activity in patients with chronic hepatitis. World J Gastroenterol 2005; 11: 7351-4.

29. Ferré N, Marsillach J, Camps J, et al. Paraoxonase-1 is associated with oxidative stress, fibrosis and FAS expression in chronic liver diseases. J Hepatol 2006; 45: 51-59.

30. Kumru S, Aydin S, Gursu MF, Ozcan Z. Changes of serum paraoxonase (an HDL-cholesterol-associated lipophilic antioxidant) and arylesterase activities in severe preeclamptic women. Eur J Obstet Gynecol Reprod Biol 2004; 114(2): 177-81.

31. Kaya S, Sütçü R, Çetin ES, et al. Relationship Between Viral Load and Lipid Peroxidation and Antioxidant Enzymes in Patients Infected with Hepatitis B Virus. Türk Klinik Biyokimya Derg 2006; 4: 77-82.

32. Levent G, Ali A, Ahmet A, et al. Oxidative stress and antioxidant defense in patients with chronic hepatitis $\mathrm{C}$ patients before and after pegylated interferon alfa-2b plus ribavirin therapy. J Transl Med 2006; 4: 25.

33. Yesilova Z, Yaman H, Oktenli C, et al. Systemic markers of lipid peroxidation and antioxidants in patients with non-alcoholic fatty liver disease. Am J Gastroenterol 2005; 100: 850-55.

34. Chrobot AM, Szaflarska-Szczepanik A, Drewa G. Antioxidant defense in children with chronic viral hepatitis B and C. Med Sci Monit 2000; 6: 713-18.

35. Karabulut AB, Sömmez E, Bayindir Y, Gözükara E. A comparison of erythrocyte superoxide dismutase and catalase activity in patients with hepatitis $\mathrm{C}$ infection. Turkish Journal of Medical Sciences 2002; 32: 313-6.

36. Baskol G, Baskol M, Kocer D. Oxidative stress and antioxidant defenses in serum of patients with non-alcoholic steatohepatitis. Clin Biochem 2007; 40: 776-80.

37. Boya $\mathrm{P}$, de la Peña A, Beloqui $\mathrm{O}$, et al. Antioxidant status and glutathione metabolism in peripheral blood mononuclear cells from patients with chronic hepatitis C. J Hepatol. 1999; 31: 80814.

38. Ko WS, Guo CH, Yeh MS, et al. Blood micronutrient, oxidative stress, and viral load in patients with chronic hepatitis C. World J Gastroenterol 2005; 11: 4697-4702.

39. Czuczejko J, Zachara BA, Staubach-Topczewska E, Halota W, Kedziora J. Selenium, glutathione and glutathione peroxidases in blood of patients with chronic liver diseases. Acta Biochim Pol 2003; 50: 1147-54.

40. Romero FJ, Bosch-Morell F, Romero MJ, et al. Lipid peroxidation products and antioxidants in human disease. Environ Health Perspect. 1998; 106 Suppl 5 (Suppl 5): 1229-34.

41. Zuwała-Jagiełło J, Pazgan-Simon M, Simon K, Warwas M. Elevated advanced oxidation protein products levels in patients with liver cirrhosis. Acta Biochim Pol 2009; 56: 679-85.
42. Llurba E, Gratacós E, Martín-Gallán P, Cabero L, Dominguez C. A comprehensive study of oxidative stress and antioxidant status in preeclampsia and normal pregnancy. Free Radic Biol Med 2004; 37: 557-70.

43. Sögüt $\mathrm{S}$, Aydin E, Elyas H, et al. The activities of serum adenosine deaminase and xanthine oxidase enzymes in Behcet's disease. Clin Chim Acta 2002; 325: 133-38.

44. Ou SY, Jackson GM, Jiao X, Chen J, Wu JZ, Huang XS. Protection against oxidative stress in diabetic rats by wheat bran feruloyl oligosaccharides. J Agric Food Chem 2007; 55: 3191-95.

45. Baldus S, Köster R, Chumley P, et al. Oxypurinol improves coronary and peripheral endothelial function in patients with coronary artery disease. Free Radic Biol Med 2005; 39: 1184-90.

46. Battelli MG, Musiani S, Valgimigli M, et al. Serum xanthine oxidase in human liver disease. Am J Gastroenterol 2001; 96 : 1194-9.

47. El-Sherif AM, Abou-Shady MA, Al-Bahrawy AM, Bakr RM, Hosny AM. Nitric oxide levels in chronic liver disease patients with and without oesophageal varices [published correction appears in Hepatol Int 2008; 2: 395-6]. Hepatol Int 2008; 2: 34145

48. Yadav D, Hertan HI, Schweitzer P, Norkus EP, Pitchumoni CS. Serum and liver micronutrient antioxidants and serum oxidative stress in patients with chronic hepatitis C. Am J Gastroenterol 2002; 97: 2634-39.

49. Fujita N, Sugimoto R, Ma N, et al. Comparison of hepatic oxidative DNA damage in patients with chronic hepatitis B and C. J Viral Hepat 2008; 15: 498-07.

50. Kitada T, Seki S, Iwai S, Yamada T, Sakaguchi H, Wakasa K. In situ detection of oxidative DNA damage, 8-hydroxydeoxyguanosine, in chronic human liver disease. J Hepatol 2001; 35: 613-8. 